\title{
Changing Patterns of Tumor Necrosis Factor Inhibitor Use in 9074 Patients with Rheumatoid Arthritis
}

\author{
YUSUF YAZICI, SVETLANA KRASNOKUTSKY, JAIME P. BARNES, PATRICIA L. HINES, JASON WANG, \\ and LISA ROSENBLATT
}

\begin{abstract}
Objective. Patients with rheumatoid arthritis (RA) commonly switch between tumor necrosis factor (TNF) inhibitors after failing to control disease activity. Much of the clinical data that support switching to a second TNF agent when one agent fails to work has come from small, short-term studies. We utilized a US insurance claims database to determine patterns of use such as dose escalation, time to discontinuation, and switching between TNF inhibitors in patients with RA.

Methods. A retrospective analysis was performed using an insurance claims database in the US from 2000 to 2005 . TNF inhibitor use, time to switch, dose escalation, and continuation times were analyzed in patients with RA.

Results. Nine thousand seventy-four patients with RA started TNF inhibitors during the period 2000 to 2005. Etanercept was the most commonly used TNF inhibitor; infliximab had the highest duration of continuation, about $50 \%$ at 2 years. In addition, infliximab showed higher rates of dose escalation compared to etanercept and adalimumab. For all TNF inhibitors, time to switching decreased from 2000 to 2005.

Conclusion. TNF inhibitor use patterns changed from 2000 to 2005, with more frequent changes among the different TNF inhibitors and a shorter duration of treatment before the change. Only about $50 \%$ of TNF inhibitors are still continued at 2 years, reflecting the difference between randomized clinical trials and real-world experience. (First Release April 1 2009; J Rheumatol 2009;36:907-13; doi:10.3899/jrheum.080592)
\end{abstract}

Key Indexing Terms:

RHEUMATOID ARTHRITIS SWITCHING

Tumor necrosis factor- $\alpha$ (TNF- $\alpha$ ) is a central cytokine in the pathogenesis of rheumatoid arthritis (RA). The use of anti-TNF therapies has significantly improved the treatment of signs and symptoms of RA and retardation of radiographic progression ${ }^{1}$. Currently, 3 anti-TNF agents are approved for the treatment of RA: etanercept, infliximab, and adalimumab. Although these 3 drugs target TNF, each has distinct structures and differences in dosing, pharmacokinetics, binding, and mechanisms of action ${ }^{1}$. The recommended dose of etanercept for RA is $25 \mathrm{mg}$ twice weekly or $50 \mathrm{mg}$ given subcutaneously per week, whereas infliximab and adalimumab have flexible dosing. Infliximab maintenance dose is 3 $\mathrm{mg} / \mathrm{kg}$ intravenously every 8 weeks but may be adjusted up to $10 \mathrm{mg} / \mathrm{kg}$ every 4 weeks as needed. Adalimumab dose is $40 \mathrm{mg}$ every 2 weeks, which may be increased to $40 \mathrm{mg}$ every week if needed.

Most treatment decisions in RA care are based on data

From the New York University Hospital for Joint Diseases, New York, New York; and Bristol-Myers Squibb, Princeton, New Jersey, USA.

Y. Yazici, MD; S. Krasnokutsky, MD, New York University Hospital for

Joint Diseases; J.P. Barnes, MPH; P.L. Hines; J. Wang, PhD;

L. Rosenblatt, MD, MPH, Bristol-Myers Squibb.

Address reprint requests to Dr. Y. Yazici, NYU Hospital for Joint Diseases,

246 East 20th Street, New York, NY 10003.

E-mail: yusuf.yazici@nyumc.org

Accepted for publication December 17, 2008.

\section{TUMOR NECROSIS FACTOR INHIBITORS DOSE ESCALATION}

obtained from randomized clinical trials (RCT). However, the limitations of RCT (e.g., the study of selected populations and short study durations) necessitate data from "real-world" patients to fully determine the role of medications, including disease modifying antirheumatic drugs (DMARD) in the treatment of RA ${ }^{2}$.

Patients who do not respond, stop responding, or have adverse events with one anti-TNF agent are often switched to another agent. These treatment changes continue in clinical practice despite the lack of controlled studies that may substantiate the benefits of switching. One survey revealed that over $94 \%$ of practicing rheumatologists in the US reported switching from one TNF inhibitor to another due to inadequate response or side effects ${ }^{3}$. Several other small studies $^{4,5}$ and 2 large prospective cohort studies ${ }^{6,7}$ support and cast doubt on the practice of switching among anti-TNF agents. Further, some recent data suggest that if patients stop treatment with a TNF antagonist due to an adverse event, rather than loss of efficacy or no response at all, the chances of the second TNF antagonist being effective may be increased $^{6-8}$. Much of the data support switching to a second TNF agent after failure of another agent; however, these results have been reported mostly in small, short-term studies that have focused on efficacy outcomes, not TNF inhibitor survival in the "real-world" 
In order to study real-world treatment patterns in the US, we used an insurance claims database to analyze patterns of use of anti-TNF inhibitors, such as dose escalation, switching between agents, and time to discontinuation among 9074 new patients with RA who were started on a TNF inhibitor. This report evaluates the largest cohort to date of patients with RA treated with a TNF inhibitor.

\section{MATERIALS AND METHODS}

A retrospective analysis was performed on 2 cohorts using the PharMetrics managed-care integrated insurance claims database. The PharMetrics database consists of claims data from over 90 managed-care organizations, covering more than 50 million patients. These database records are generally representative of the national, commercially insured population in terms of age, sex, and type of health plan.

Patients were included in Cohort 1 if (1) they had a prior RA diagnosis (International Classification of Diseases-9-CM 714.XX) and initiated TNF inhibitor treatment between January 1, 2000, and July 1, 2005; and (2) they had plan eligibility for 3 months prior to and a minimum of 6 months following the index date. TNF inhibitor treatments were identified by the National Drug Code (NDC; agent obtained through a pharmacy) or Healthcare Common Procedure Coding System J-code (agent obtained and administered in a medical setting) entered on a claim. The index date was defined as the first TNF antagonist claim between January 1, 2000, and July 1, 2005. Eligible patients were followed through the end of continuously eligible claims. Incident cohorts were defined by year of first TNF claim. Treatment persistence (continuation) was defined as days of continuous therapy from the date of first TNF claim. Patients were considered to be persistent until the end of the eligible claims (i.e., censored) until a 30-day treatment gap after exhaustion of the previous prescribed supply, or until switching treatment.

A treatment pattern analysis was also performed on Cohort 2, a subsidiary cohort using the 2003 to 2005 patient extract. This approach helped to facilitate the inclusion of all 3 TNF inhibitors, for adalimumab had not been available until 2003. The date of the first TNF antagonist claim with prior RA diagnosis from January 1, 2003, to July 1, 2005, was defined as the index date. Patients were followed through the end of continuously eligible claims to examine treatment patterns. The same persistence definition as above was also applied in this analysis. An additional analysis using Cohort 2 examined the incidence of increased medication use or "dose escalation." Dose escalation was defined as an increase in dose at each administration, an increased frequency of drug administration, or both. When there was a dose increase and frequency decrease or dose decrease and frequency increase, the information was considered undetermined, for the final dose used by the patient was unclear. Since administrative claims for infusions given in a medical setting do not provide information on dose or quantity given, a change in the total charge of infusion by approximate average charge per vial (US $\$ 500$ for infliximab, US $\$ 150$ for etanercept, based on distribution of charged amounts in the data) or more was used to define dose increase or decrease. The assumption was that this increase/decrease in charge corresponded to an increase/decrease in number of vials at that infusion. All adalimumab and most etanercept claims retrieved for the cohorts were pharmacy-based (i.e., NDC-identified dose and the "quantity dispensed" fields were populated); no approximation using charges was needed for these cases.

For the switching pattern analysis, a subgroup of patients from Cohort 2 was included with plan eligibility for 3 months prior to the index date and a minimum of 18 months of available claims post-index date. Treatment and switch patterns of TNF inhibitors were examined by descriptive analysis, including days on the initial medication, number of patients who switched medications, and time to first switch. Medication persistence by index medication and by year of index was examined using Kaplan-Meier curves. Further, treatment patterns of TNF inhibitors by year of index were described.
All statistical analyses were performed using SAS v8.2. Rank statistics (i.e., median) were reported as the commonly accepted method for handling censored data.

\section{RESULTS}

TNF inhibitor use and duration of treatment patterns. In Cohort 1, 9074 patients with RA started TNF antagonists from 2000 to 2005. Mean age was $48.2( \pm 12.5)$ years, and $74 \%$ were female (Table 1). For the entire cohort, etanercept was the most commonly prescribed initial TNF antagonist; $4643(51.2 \%)$ patients were started on etanercept. A total of $1365(15.0 \%)$ patients were treated with adalimumab and 3066 (33.8\%) patients were given infliximab. Table 2 shows the trend in TNF prescription and time to switching patterns for each year from 2000 to 2004 (partial-year data from 2005 show similar trends).

For Cohort 2, when 3 TNF inhibitors were commercially available, 6070 patients started taking an anti-TNF: 3073 $(50.6 \%)$ patients started etanercept, 1632 (26.9\%) infliximab, and 1365 (22.5\%) adalimumab.

For Cohort 1 (i.e., the entire study population), infliximab had the highest percentage of continuation, yet only $50 \%$ of patients were still on treatment after 2 years (Figure 1). A similar pattern was observed for Cohort 2, where infliximab had the highest percentage of continuation (Figure 2). During the time period when adalimumab was not available, patients tended to continue infliximab longer than other TNF agents, but the duration on treatment was decreased for both etanercept and infliximab (Figure 3).

TNF inhibitor dose escalation patterns. Table 3 shows the patterns of dose and interval change for each TNF inhibitor for Cohort 2. For both etanercept and adalimumab, more than $60 \%$ of patients remained on the initial dose at the original frequency. For etanercept patients, 38\% changed their dosing schedule but remained on the same overall dose, whereas $18 \%$ of adalimumab patients had an actual increase in dose. Among infliximab-treated patients, close to $40 \%$ increased either the infusion frequency or the dose of each infusion, or both. Only $27 \%$ of infliximab-treated patients continued the initial starting doses; close to $25 \%$ decreased their doses.

TNF inhibitor switching patterns. The 18-month subanalysis of Cohort 2 included 4620 patients (mean age $48.1 \pm$ $12.0 \mathrm{yrs}$, females $75 \%$ ). Table 4 shows the trends of TNF inhibitor use and switching patterns. Patients were administered infliximab longer than etanercept or adalimumab (median 464 days on infliximab, 347.5 days on etanercept, 365 days on adalimumab; $\mathrm{p}<0.0001$ ), and fewer patients switched from infliximab to another agent (10.0\%, versus $12.5 \%$ for etanercept and $15.1 \%$ for adalimumab; $\mathrm{p}<$ 0.0001). Of the patients who switched, infliximab-treated patients had a longer time to switch than both etanercept and adalimumab users. Most etanercept patients who switched TNF inhibitors switched to adalimumab $(8.1 \%$, versus $4.5 \%$ 
Table 1. Baseline characteristics, 2000-2005.

\begin{tabular}{|c|c|c|c|c|c|c|c|c|}
\hline \multicolumn{9}{|l|}{ Characteristic } \\
\hline \multicolumn{9}{|c|}{ Mean age at index, yrs; n, mean (SD) } \\
\hline All patients* & \multicolumn{2}{|c|}{9005} & \multicolumn{6}{|l|}{$49(11.97)$} \\
\hline ETA & \multicolumn{2}{|c|}{4585} & \multicolumn{6}{|l|}{$47(12.247)$} \\
\hline ADA & \multicolumn{2}{|c|}{1365} & \multicolumn{6}{|l|}{$49(9.977)$} \\
\hline IFX & \multicolumn{2}{|c|}{3055} & $\begin{array}{c}49(9.977) \\
50(12.102)\end{array}$ & & & & & \\
\hline Sex, n (\%) & \multicolumn{2}{|c|}{ Female } & \multicolumn{6}{|l|}{ Male } \\
\hline All patients** & \multicolumn{2}{|c|}{$6720(74.06)$} & \multicolumn{6}{|l|}{$2353(25.93)$} \\
\hline ETA & \multicolumn{2}{|c|}{$3415(73.55)$} & \multicolumn{6}{|l|}{$1228(26.45)$} \\
\hline ADA & \multicolumn{2}{|c|}{$1050(76.92)$} & \multicolumn{6}{|l|}{$315(23.08)$} \\
\hline IFX** & \multicolumn{2}{|c|}{$2255(73.55)$} & \multicolumn{6}{|l|}{$810(26.42)$} \\
\hline \multicolumn{3}{|c|}{ Patients per index year, n (\%) 2000} & 2001 & 2002 & \multicolumn{2}{|c|}{2003} & 2004 & 2005 \\
\hline \multicolumn{2}{|c|}{ All patients } & 695 (7.66) & $1126(12.41) 118$ & $183(13.04)$ & 2881 & $(31.75)$ & $2698(29.73)$ & $491(5.41)$ \\
\hline \multicolumn{2}{|l|}{ ETA } & $568(12.23)$ & $555(11.95) \quad 44$ & 447 (9.63) & 1558 & (33.56) & $1326(28.56)$ & $189(4.07)$ \\
\hline \multicolumn{2}{|l|}{$\mathrm{ADA}$} & $0(0)$ & $0(0)$ & $0(0)$ & 552 & (40.44) & $666(48.79)$ & $147(10.77)$ \\
\hline \multicolumn{2}{|l|}{ IFX } & \multirow{2}{*}{$\begin{array}{l}127(4.14) \\
\text { East coast }\end{array}$} & $571(18.62) \quad 73$ & $736(24.01)$ & 771 & $25.15)$ & $706(23.03)$ & $155(5.06)$ \\
\hline \multicolumn{2}{|c|}{ Region at index, $\mathrm{n}(\%)$} & & Mid-West & South $\mathrm{Ce}$ & entral & West & Coast & \\
\hline \multicolumn{2}{|l|}{ All patients } & $2185(24.08)$ & $3719(40.99)$ & 2597 & 8.62) & 573 & $(6.31)$ & \\
\hline ETA & & $1099(23.67)$ & ) $1929(41.55)$ & $1292(27$ & 7.83) & 323 & $(6.96)$ & \\
\hline ADA & & $408(29.89)$ & $549(40.22)$ & $324(23$ & 3.74) & $84(6$ & $6.15)$ & \\
\hline IFX & & $678(22.11)$ & $1241(40.48)$ & 981 & & 166( & $(5.41)$ & \\
\hline Payer type at inde & $\mathrm{x}, \mathrm{n}(\%)$ & Commercial & 1 Medicare Risk & k Medicare & e Gap & Othe & r*** & \\
\hline All patients & & $7338(81.1)$ & $504(5.57)$ & $11(0.1$ & 12) & 1190 & (13.15) & \\
\hline ETA & & 3777 (81.61) & $188(4.06)$ & $2(0.0$ & & 661 & 14.28) & \\
\hline $\mathrm{ADA}$ & & 1203 (88.59) & $26(1.91)$ & $0(0)$ & & 129 & $(9.5)$ & \\
\hline IFX & & $2358(77.13)$ & $290(9.49)$ & $9(0.2$ & & $400(1$ & $13.08)$ & \\
\hline
\end{tabular}

* 69 patients had unevaluable birthdates. ** Sex of 1 patient was unknown. *** Includes Medicaid, self-insured, and unknown. ETA: etanercept, IFX: infliximab, ADA: adalimumab.

Table 2. Patterns of use and duration taking anti-TNF medications. Data are median days (75th-25th percentiles).

\begin{tabular}{|c|c|c|c|c|c|c|}
\hline \multicolumn{7}{|l|}{ Etanercept } \\
\hline Time to switch & $381(635.5-190)$ & $244(553-68)$ & $156(370-93.5)$ & $156(307-68)$ & $113(167-40)$ & $<0.0001$ \\
\hline \multicolumn{7}{|l|}{ Infliximab } \\
\hline Time on 1st TNF (total cohort) & 483 (793-209) & $469(770-240)$ & $343(858.5-197)$ & $581(775-217)$ & $328(455-184)$ & $<0.0001$ \\
\hline Time on 1st TNF (total cohort) & $*$ & $*$ & $*$ & $371(670-131)$ & $280(397.5-148)$ & $<0.0001$ \\
\hline Time to switch & $*$ & $*$ & $*$ & $136(266-43)$ & $97(197-62)$ & 0.02 \\
\hline
\end{tabular}

to infliximab; $\mathrm{p}<0.0001)$, and most patients taking adalimumab switched to etanercept $(11.4 \%$, versus $3.6 \%$ to infliximab; $\mathrm{p}<0.0001)$. Patients were equally distributed when switching from infliximab to either etanercept or adalimumab (4.3\% and 5.7\%, respectively; $\mathrm{p}=0.1188)$.

\section{DISCUSSION}

Our data show several trends in TNF inhibitor use that developed from 2000 to 2005 . Etanercept was the most commonly prescribed TNF inhibitor before 2003, and despite subsequent availability of adalimumab it retained that distinction at least until 2005 (end of study period). Concerning persistency, more patients with RA continued infliximab compared to etanercept or adalimumab. However, continuation rates for all TNF inhibitors were well below those reported in $\mathrm{RCT}^{14-16}$. A trend toward quicker switching between TNF inhibitors was observed with time, along with shorter treatment durations on any of the agents. Users of injectable TNF inhibitor appeared to switch more commonly to other injectable TNF inhibitors rather than intravenously infused infliximab.

Another observation was that most patients treated with etanercept and adalimumab continued the initial starting doses. However, $40 \%$ of the infliximab-treated patients had 


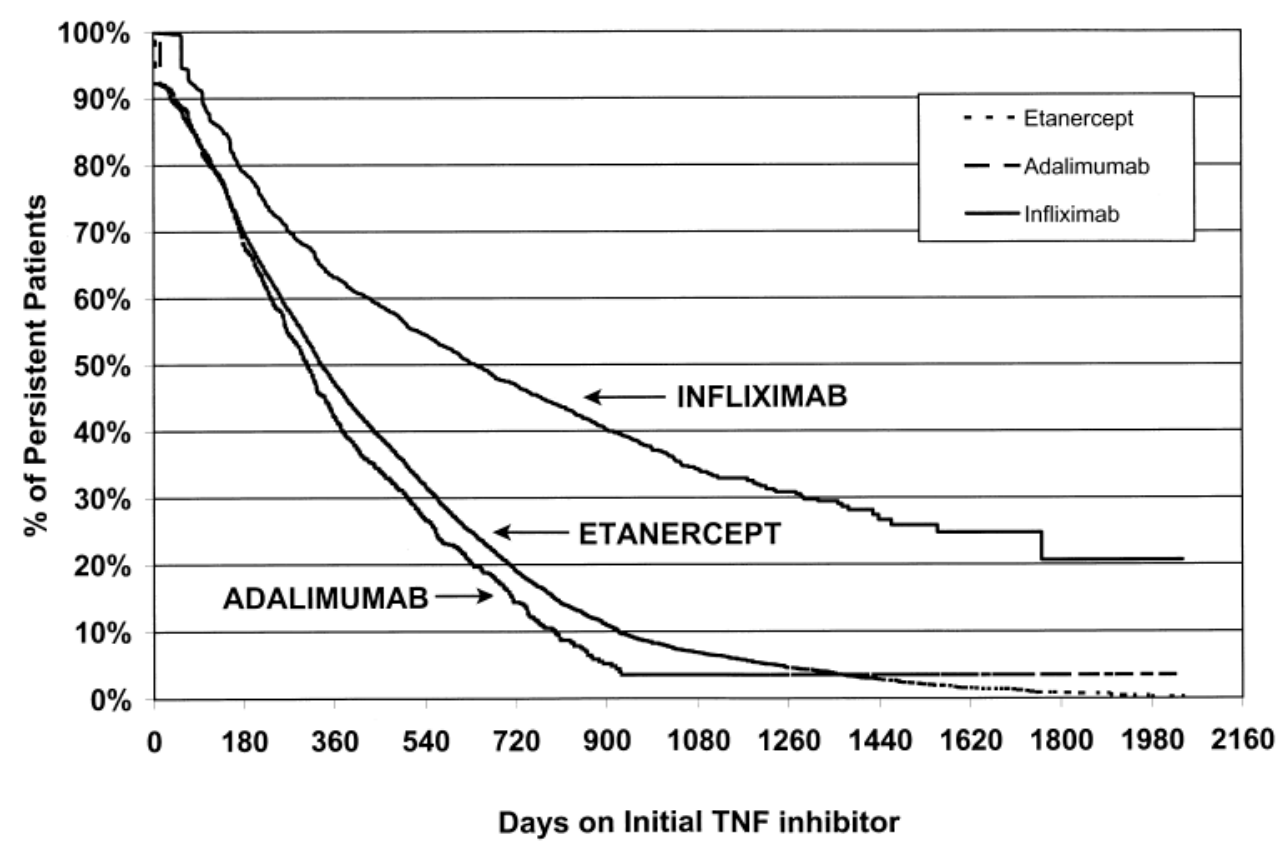

Figure 1. Continuation on the initial TNF inhibitor during 2000-2005. Persistence taking infliximab was significantly different from persistence on etanercept or adalimumab. Persistence on each of the 3 anti-TNF inhibitors was significantly different from the others $(\mathrm{p}=0.0007)$.

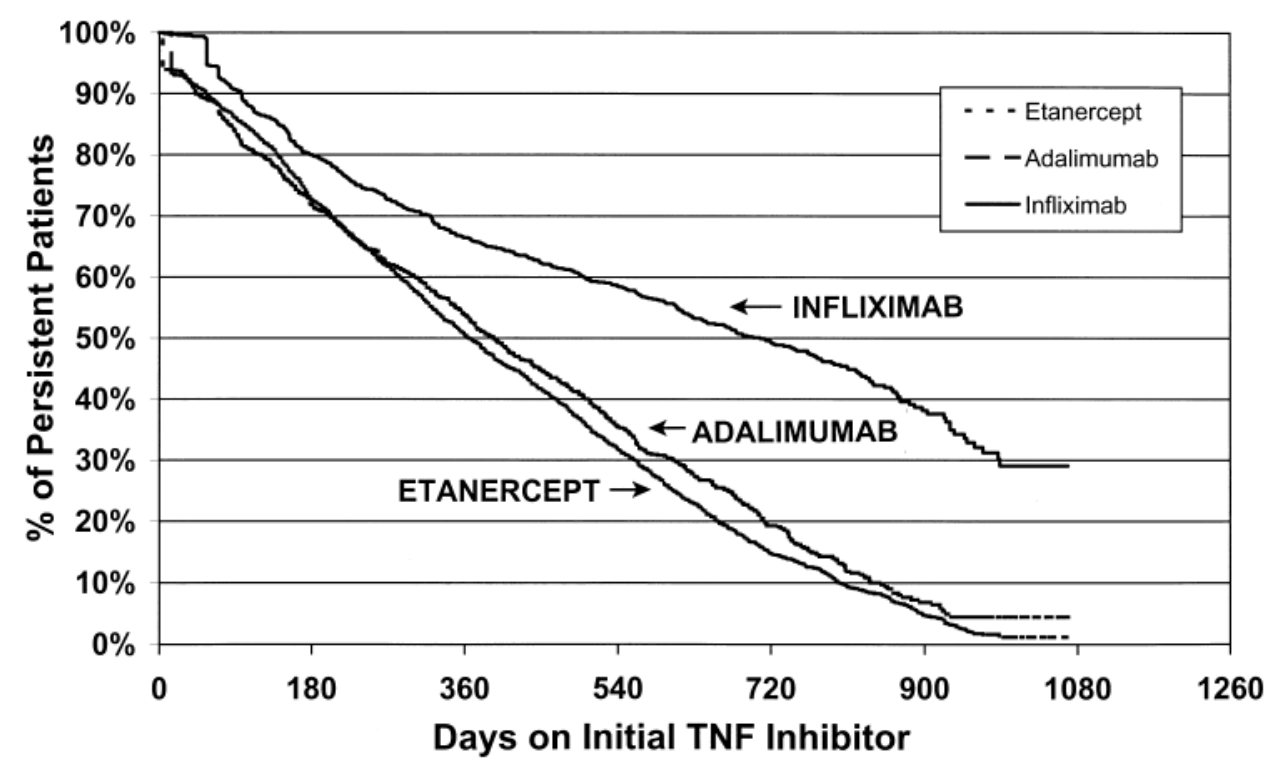

Figure 2. Continuation on the initial TNF inhibitor during 2003-2005. Persistence taking infliximab was significantly different from persistence on etanercept or adalimumab.

a dose escalation, with only $27 \%$ still taking starting doses of infliximab. This may partially explain why patients tended to stay on infliximab longer - they were able to receive increased dose and/or frequency of infusion (as per label) if additional efficacy was needed, rather than switching to another agent. Frequent dose escalation in users of infliximab has important implications, given the drug and administration costs associated with more medication use. The reasons for these dose changes need to be elaborated further in other large cohort studies, along with the cost-effectiveness of using infliximab when dose escalation occurs.

Another reason patients may have been more persistent is that infliximab is an infusible agent, which requires regular physician followup (4-8 weeks) for administration. Seeing a physician regularly may encourage a patient to remain on their regimen. Other infusible agents not available during Personal non-commercial use only. The Journal of Rheumatology Copyright @ 2009 . All rights reserved. 


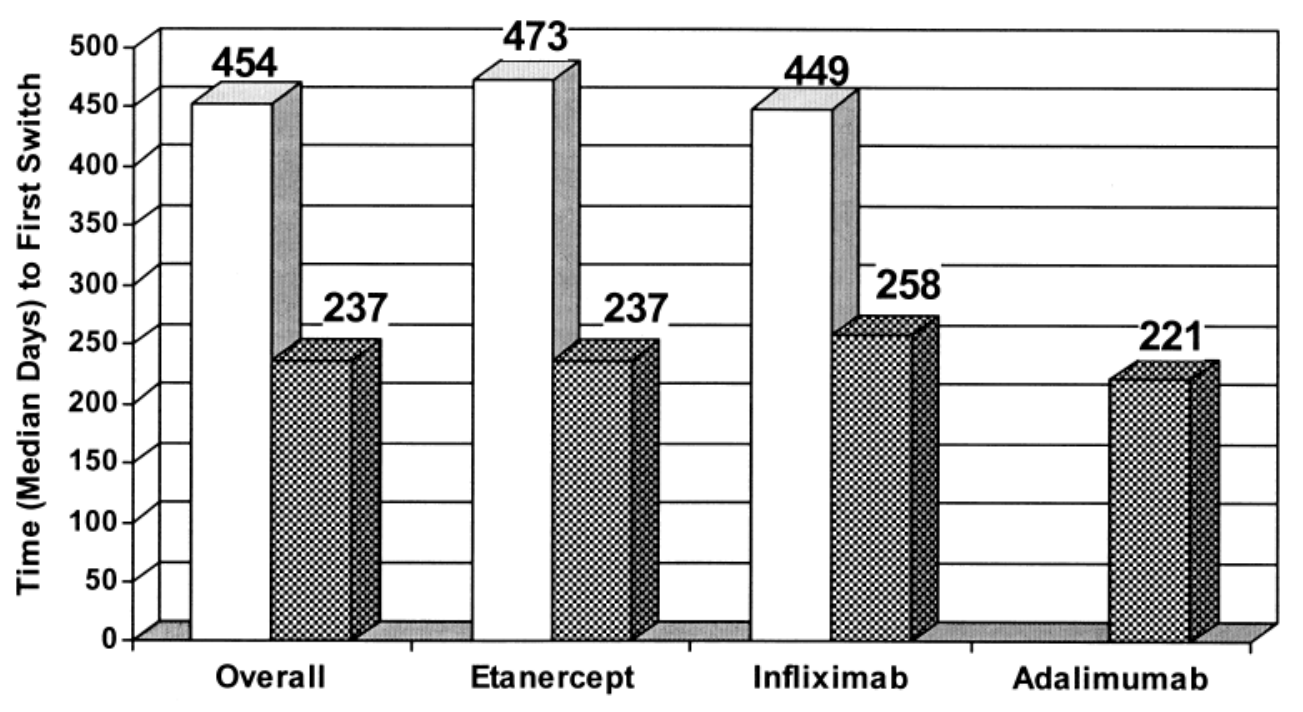

口Pre-Adalimumab $\otimes$ Post-Adalimumab

Figure 3. Comparison of time to first switch of therapy before and after adalimumab availability. Differences were not significant.

Table 3. Patterns of dose/frequency change 2003-2005.

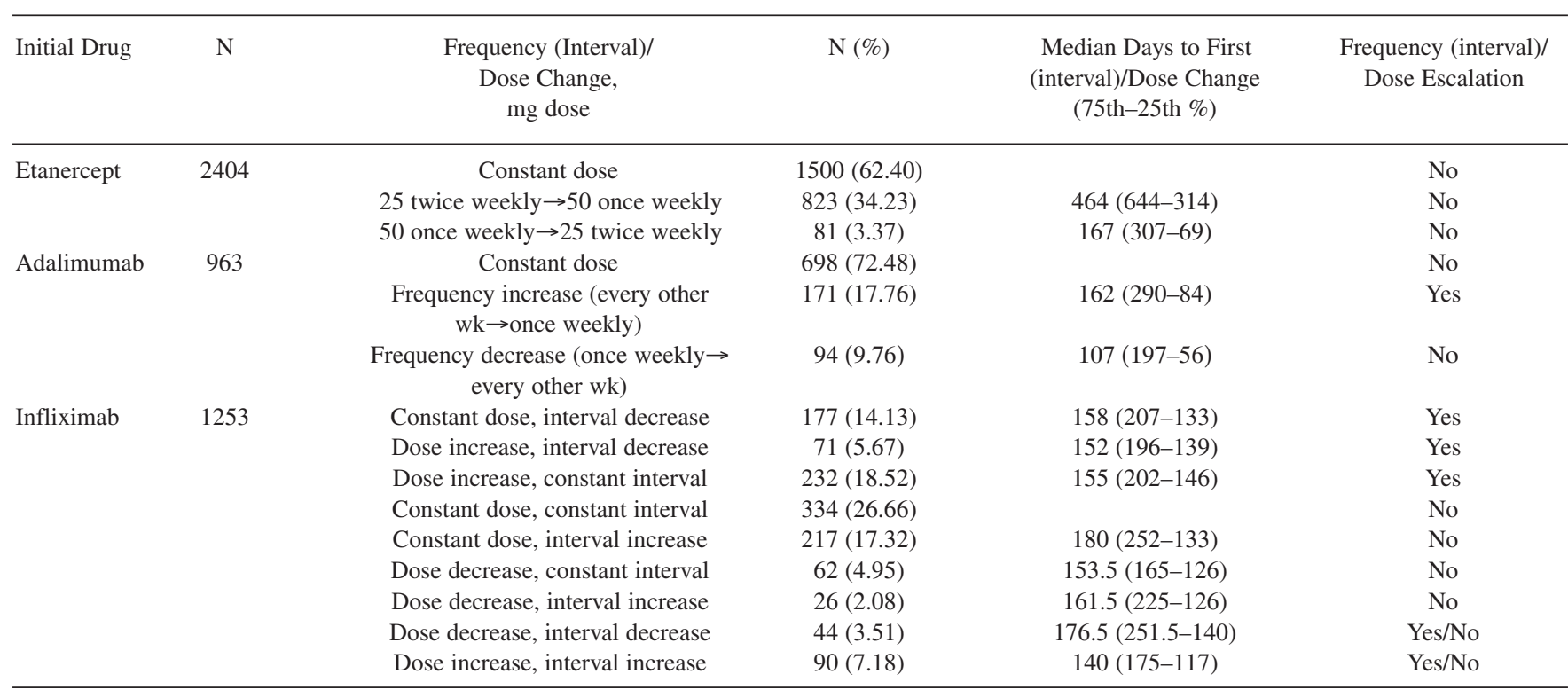

the study period (abatacept, rituximab) are now indicated for RA. It would be worthwhile to investigate whether these infusible agents also have better persistency than the subcutaneous injections.

One strength of this report is that the time period and sample size examined are greater than in most published reports regarding TNF inhibitor use. A shortcoming of utilizing insurance claims databases is that substantiated evidence for discontinuation, switching, or dose escalation patterns does not exist or is not available. In addition, current information about patient disease characteristics does not examine concurrent DMARD use; thus, no recommendations can be made with regard to individual patients or the disease activity level at which these changes should be initiated. This notion is an important consideration for everyday practice. The robust numbers of patients over our 5-year study period, however, revealed some trends in TNF inhibitor use. These data should be used as hypothesis-generating, rather than as reporting firm conclusions.

A separate study of compliance and dosage administration found that patients taking infliximab were more compliant than those taking etanercept, but that etanercept had 
Table 4. Patterns of TNF switching and time to switch 2003-2005.

\begin{tabular}{|c|c|c|c|c|c|}
\hline Initial Drug & $\mathrm{N}$ (total) & $\begin{array}{c}\text { Median Days on } \\
\text { Initial Drug } \\
(75 \text { th-25th \%), Total Cohort }\end{array}$ & First Switch & $\mathrm{N}(\%)$ & $\begin{array}{l}\text { Median Days to } \\
\text { First Switch } \\
\text { (75th-25th \%) }\end{array}$ \\
\hline \multirow{3}{*}{ Etanercept } & \multirow{3}{*}{2404} & \multirow{3}{*}{$347.5(578-158.5)$} & No Switch & $2103(87.48)$ & $388(606-187)$ \\
\hline & & & Adalimumab & $194(8.07)$ & $151.5(280-70)$ \\
\hline & & & Infliximab & $107(4.45)$ & $127(291-64)$ \\
\hline \multirow[t]{3}{*}{ Adalimumab } & \multirow{3}{*}{963} & \multirow[t]{3}{*}{$365(569-143)$} & No Switch & $818(84.94)$ & $412(607-184)$ \\
\hline & & & Etanercept & $110(11.42)$ & $114(232-55)$ \\
\hline & & & Infliximab & $35(3.63)$ & $141(243-70)$ \\
\hline \multirow[t]{3}{*}{ Infliximab } & \multirow[t]{3}{*}{1253} & \multirow[t]{3}{*}{$464(693-210)$} & No Switch & $1128(90.02)$ & $504.5(718-231)$ \\
\hline & & & Etanercept & $54(4.31)$ & 145 (307-74) \\
\hline & & & Adalimumab & $71(5.67)$ & $185(330-88)$ \\
\hline
\end{tabular}

fewer changes in dosage ${ }^{17}$. This study also found that patients taking infliximab tended to be older and have more comorbidities (and higher pre-index medical costs), although it was not established how these differences may have affected results. In our study population, mean age for each anti-TNF was similar (47, 49, and 50 years for etancercept, adalimumab, and infliximab, respectively), so that age was unlikely to have an effect on outcomes.

In addition, 9\% of patients taking infliximab had Medicare coverage, compared with $4 \%$ taking etanercept and $2 \%$ taking adalimumab. While the proportion of infliximab patients with Medicare was greater than for the subcutaneous drugs, this proportion was still small relative to the commercially-covered infliximab population (77\%), and therefore was not likely to have a large influence on overall treatment patterns. The study by Harley, et al had 31.9\% of patients on Medicare, but they did not establish a relationship between insurance coverage and compliance ${ }^{17}$. It is, of course, possible and even likely that different plan restrictions and benefit designs would have an influence on treatment patterns and persistency. However, the plans in the PharMetrics database are anonymous, and benefit designs are not included with the data.

Because this study was descriptive, the authors did not examine comorbidities; however, we can see from Harley, et $a l$ that it was difficult to make a connection between comorbidities and compliance. It is possible, however, that increased age or comorbidities, which some may translate into more severe RA or RA of longer duration, would result in increased persistency due to determination to alleviate symptoms. This concept would need further study.

The overall trends from the data in our analysis may have several explanations. First, increased expectations on the part of the patient or the physician could play a role in creating impatience when immediate results are not seen with a given anti-TNF inhibitor. The success that has been achieved in the treatment of RA over the last 10 to 15 years and results from clinical trials may have increased such expectations. Second, the changing type of patient being considered for TNF therapies may be part of the explana- tion. Initially, TNF inhibitors were reserved for patients who had failed multiple DMARD, and they were seen as last-chance options. This may have led patients to continue taking agents longer than has been seen over the last 2 to 3 years. When TNF inhibitors are being used earlier in the course of disease, patients may be more determined to try other options if a treatment is not effective. In addition, having more options may trigger a faster switching response, as also observed after adalimumab became available for use.

In this analysis, the patients in the database who started taking infliximab tended to persist on this medication longer than they did on etanercept or adalimumab. The reasons for this persistence are not clear, as discussed. Previous studies have shown results mostly in favor of etanercept, which demonstrated longer survival times than other TNF inhibitors ${ }^{18-20}$. However, these studies were conducted in Europe. Two were prospective studies with clinical programs ${ }^{18,20}$, which may have encouraged patients to be more persistent due to more structured followup. The third was a chart review design ${ }^{19}$ with 442 patients (309 RA patients) from one hospital. Our study used US insurance claims data, which is a larger source of patient data and may be more generalizable to the US population. It is possible that the shortage of etanercept in the US from late 2000 to early 2003 may have had an effect on persistency early in the study (the proportion of etanercept patients that started in 2000-2002 was less than for 2003-2004; Table 1). On the other hand, the fact that approximately $10 \%$ of etanercept patients were able to initiate the drug during each shortage year would suggest that patients already taking the drug during those years were not forced to discontinue therapy.

TNF inhibitor use patterns are changing with time, with more frequent changes and shorter duration of treatment before the change. In addition, dose escalation is frequent with infliximab, which may have important financial repercussions. Further research needs to be conducted to determine if these trends remain constant with the availability of newer biologic treatment options, and how these newer treatments influence the treatment algorithm. 


\section{REFERENCES}

1. Scott DL, Kingsley GH. Tumor necrosis factor inhibitors for rheumatoid arthritis. N Engl J Med 2006;355:704-12.

2. Pincus T, Sokka T. Should contemporary rheumatoid arthritis clinical trials be more like standard patient care and vice versa? Ann Rheum Dis 2004;63 Suppl 2:ii32-ii39.

3. Kamal KM, Madhavan SS, Hornsby JA, Miller LA, Kavookjian J, Scott V. Use of tumor necrosis factor inhibitors in rheumatoid arthritis: a national survey of practicing United States rheumatologists. Joint Bone Spine 2006;73:718-24.

4. Yazici Y, Erkan D. Do etanercept-naive patients with rheumatoid arthritis respond better to infliximab than patients for whom etanercept has failed? Ann Rheum Dis 2004;63:607-8.

5. Wick MC, Ernestam S, Lindblad S, et al. Adalimumab (Humira) restores clinical response in patients with secondary loss of efficacy from infliximab (Remicade) or etanercept (Enbrel): results from the STURE registry at Karolinska University Hospital. Scand J Rheumatol 2005;34:353-8.

6. Gomez-Reino JJ, Carmona L, and the BIOBADASER Group. Switching TNF antagonists in patients with chronic arthritis: an observational study of 488 patients over a four-year period. Arthritis Res Ther 2006;8:R29.

7. Hyrich KL, Lunt M, Watson KD, Symmons DPM, Silman AJ. Outcomes after switching from one anti-tumor necrosis factor a agent to a second anti-tumor necrosis factor a agent in patients with rheumatoid arthritis: Results from a large UK national cohort study. Arthritis Rheum 2007;56:13-20.

8. Iannone F, Trotta F, Montecucco C, et al., GISEA (Gruppo Italiano per lo Studio delle Early Arthritis). Etanercept maintains the clinical benefit achieved by infliximab in patients with rheumatoid arthritis who discontinued infliximab because of side effects. Arthritis Rheum 2007;66:249-52.

9. Gomez-Puerta JA, Sanmarti R, Rodriguez-Cros JR, Canete JD. Etanercept is effective in patients with rheumatoid arthritis with no response to infliximab therapy [letter]. Ann Rheum Dis 2004;63:896.

10. Nikas SN, Voulgari PV, Alamanos Y, et al. Efficacy and safety of switching from infliximab to adalimumab: a comparative controlled study. Ann Rheum Dis 2006;65:257-60.

11. Haraoui B, Keystone EC, Thorne JC, et al. Clinical outcomes of patients with rheumatoid arthritis after switching from infliximab to etanercept. J Rheumatol 2004;31:2356-9.
12. Hansen KE, Hildebrand JP, Genovese MC, et al. The efficacy of switching from etanercept to infliximab in patients with rheumatoid arthritis. J Rheumatol 2004;31:1098-102.

13. Van Vollenhoven R, Harju A, Brannemark S, Klareskog L. Treatment with infliximab (Remicade) when etanercept (Enbrel) has failed or vice versa: data from the STURE registry showing that switching tumour necrosis factor a blockers can make sense. Ann Rheum Dis 2003;62:1195-8.

14. Genovese MC, Bathon JM, Martin RW, et al. Etanercept versus methotrexate in patients with early rheumatoid arthritis: two-year radiographic and clinical outcomes. Arthritis Rheum 2002;46:1443-50

15. van der Heijde D, Klareskog L, Rodriguez-Valverde R, et al. Comparison of etanercept and methotrexate, alone and combined, in the treatment of rheumatoid arthritis: two-year clinical and radiographic results from the TEMPO study, a double-blind, randomized trial. Arthritis Rheum 2006;54:1063-74.

16. Breedveld FC, Weisman MH, Kavanaugh AF, et al. The PREMIER study: A multicenter, randomized, double-blind clinical trial of combination therapy with adalimumab plus methotrexate versus methotrexate alone or adalimumab alone in patients with early, aggressive rheumatoid arthritis who had not had previous methotrexate treatment. Arthritis Rheum 2006;54:26-37.

17. Harley CR, Frytak JR, Tandon N. Treatment compliance and dosage administration among rheumatoid arthritis patients receiving infliximab, etanercept, or methotrexate. Am J Manag Care 2003;9 Suppl:S136-43.

18. Kristensen LE, Saxne T, Nilsson JA, Geborek P. Impact of concomitant DMARD therapy on adherence to treatment with etanercept and infliximab in rheumatoid arthritis. Results from a six-year observational study in southern Sweden. Arthritis Res Ther 2006;8:R174.

19. Brocq $\mathrm{O}$, Roux $\mathrm{CH}$, Albert $\mathrm{C}$, et al. TNF-a antagonist continuation rates in 442 patients with inflammatory joint disease. Joint Bone Spine 2007;74:148-54.

20. Geborek P, Crnkic M, Petersson IF, Saxne T for the South Swedish Arthritis Treatment Group. Etanercept, infliximab, and leflunomide in established rheumatoid arthritis: clinical experience using a structured follow up programme in southern Sweden. Ann Rheum Dis 2002;61:793-8. 